\title{
Los conceptos y la identidad de la nueva arquitectura ortodoxa serbia (1990-2009)
}

The concepts and identity of the new serbian orthodox ecclesiastical architecture (1990-2009)

Aleksandar Kadijevic y Miroslav Pantovic

https://doi.org/10.17979/aarc.2011.2.2.5051

Durante el periodo que va entre 1945 y 1990, en los tiempos del sistema comunista represivo de partido único de la antigua Yugoslavia, la construcción de nuevas iglesias que deberían haber cumplido las demandas de la Iglesia ortodoxa serbia, fue sistemáticamente dificultada y obstruida. Las autoridades comunistas, ampliamente conocidas por su ateísmo, no mostraron comprensión alguna por los sentimientos de millones de cristianos ortodoxos en el estado multinacional, expresando simultáneamente su miedo a la influencia social de la Iglesia ortodoxa serbia. Las autoridades comunistas de la antigua Yugoslavia, expresando continuamente su temor a los sentimientos nacionales serbios, además del declive de su propia influencia ideológica, trataron la construcción de nuevas iglesias como un gran peligro para el sistema de relaciones sociales pseudo igualitarias. Por otro lado, gracias a los patriotas emigrantes serbios y a sus tradicionales y cálidos sentimientos hacia su país, la construcción de nuevas iglesias continuó en algunas zonas de la antigua Yugoslavia. Sin embargo, proyectos mayores y más ambiciosos se llevaron a cabo en el extranjero, especialmente en aquelos países con una amplia diáspora serbia, como EEUU, Canadá y Australia.

En el periodo de entreguerras, la arquitectura de la Iglesia ortodoxa era creativamente fructífera, y estilística y artísticamente muy sugerente. Pero entre 1945 y mediados de los años 80 del siglo pasado, ha demostra- do un estancamiento evidente y constante. Pasaron definitivamente los tiempos de los templos e iglesias representativos y monumentales, debido a múltiples circunstancias sociales y económicas desfavorables y sin esperanza visible de que puedan retornar algún día. Simultáneamente, muchos expertos en la antigua Yugoslavia consideraron la arquitectura eclesiástica como totalmente desfasada e irrelevante. El estudio de la arquitectura religiosa, que solía ser una parte importante de la educación en la Facultad de Arquitectura de la Universidad de Belgrado, fue abolido. Además de este motivo (el bloqueo totalitario del establishment político del partido único), otro motivo que provocó el estancamiento de la arquitectura eclesiástica fue el predominio y el largo reinado de la ideología de la modernidad arquitectónica, favorecida y popularizada por el régimen oficial como una clase de arquitectura estatal cuyos protagonistas expresaban una animosidad abierta y sin ambages hacia la construcción de iglesias ortodoxas.

Las condiciones generales comenzaron a mejorar durante la década de los años ochenta del siglo pasado, cuando la disciplina ideológica y burocrática estatal empezó a entrar en declive. Resultó de crucial importancia la muerte del dictador Josip Broz Tito, que había permanecido largo tiempo en su cargo (falleció en 1980), así como las muestras evidentes de pluralismo político. No obstante, el acontecimiento más importante 
Fig. 1. Bogdan Nestorovic y Aleksandar Deroko (original); Branko Pesic y Vojislav Milovanovic (actual), Catedral de San Sava, Belgrado, 1926/2009.

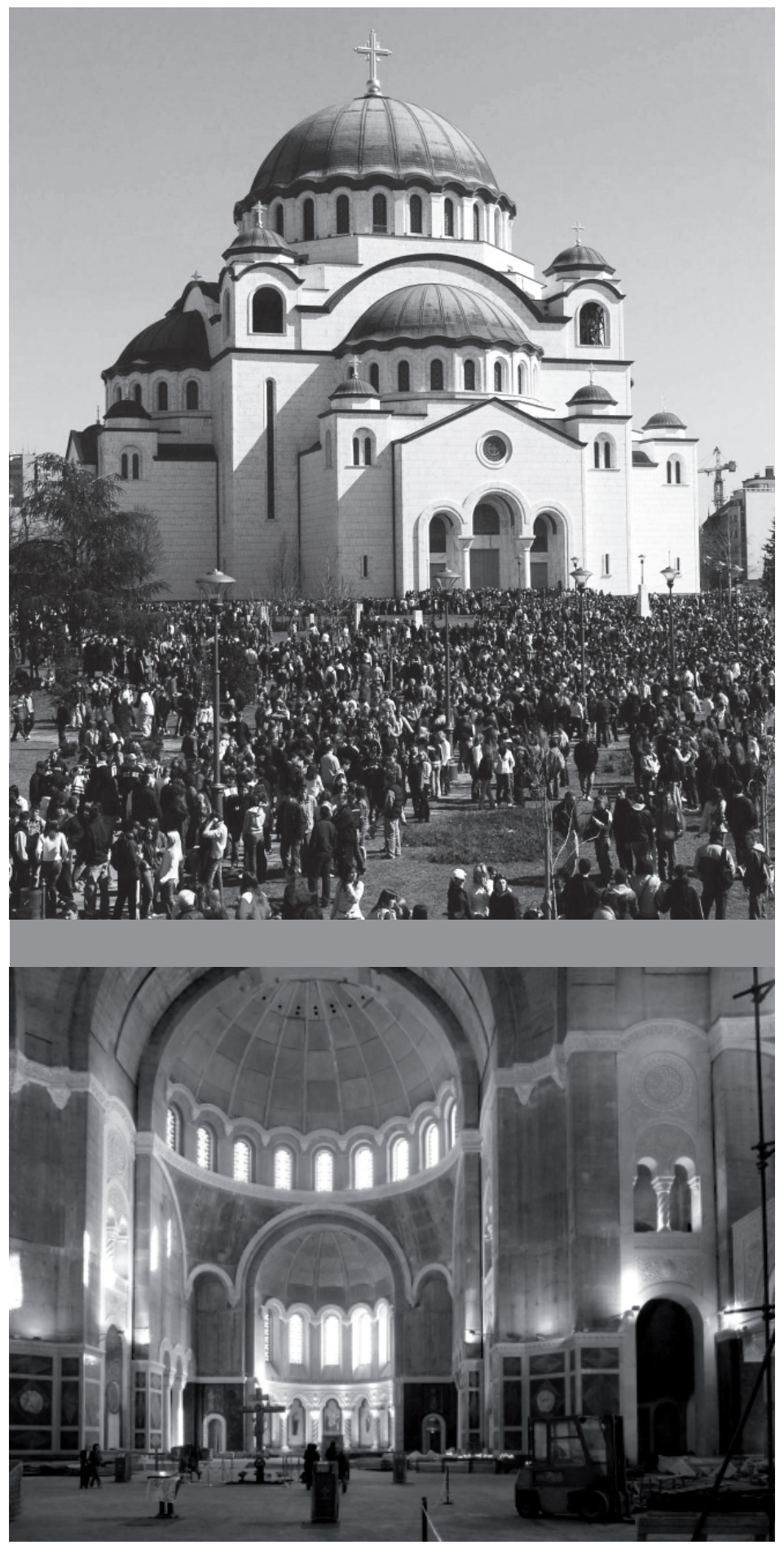




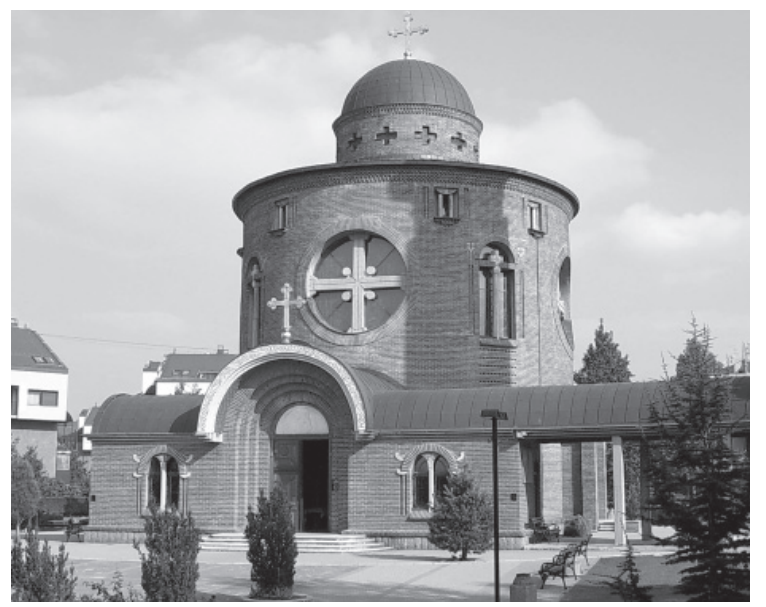

Fig. 2. Mihajlo Mitrovic, San Basilio de Ostrog, Belgrado, 1996/2002.

y que significó una reversión de la política estatal hacia la Iglesia ortodoxa serbia fue el permiso para terminar la construcción del templo de San Sava, en el distrito de Vracar, en la capital Belgrado. Se concedió el permiso el 19 de junio de 1984, después de ochenta y ocho solicitudes oficiales del patriarca alemán dirigidas a las autoridades estatales. Obstruida durante décadas, la construcción del mayor templo ortodoxo en toda la región se convirtió en misión prioritaria y de importancia excepcional. Después de todo, el post-modernismo tardío en la cultura serbia y la variedad de teorías artísticas históricas y regionales dio un nuevo estímulo a la renovación de la conciencia religiosa y a los conceptos de la arquitectura eclesiástica. La construcción de templos ortodoxos experimentó un renacimiento a finales de los ochenta, gracias al declive del sistema político totalitario. Esto, a su vez, provocó un despertar de la conciencia nacional serbia, el refuerzo del papel social de la Iglesia y una mayor voluntad de hacer donaciones y establecer los cimientos para la construcción de iglesias y templos. Desde entonces, varios cientos de iglesias ortodoxas de diversos tipos fueron erigidas en toda la antigua Yugoslavia, mientras que se reconstruían simultáneamente una cantidad significativa de iglesias devastadas o inacabadas. Tras cinco décadas de negligencia sistemática, la construcción de iglesias experimentó un renacimiento, y los medios de comunicación la exaltaron y la popularizaron. Además, esta tendencia cobró un nuevo impulso no sólo en Serbia, sino también en otras regiones de la antigua Yugoslavia.

Tras años de opresión, la Iglesia, su jerarquía y sus constructores consiguieron recobrar la dignidad perdida, lo cual trajo como consecuencia una gran cantidad de firmas arquitectónicas especializadas. Esto, a su vez, sacó a la luz a nuevos expertos, cuyo interés principal era el de explorar y continuar desarrollando la arquitectura sacra. A pesar de ello, no logró desarrollar ninguna matriz teológica, ideológica u original de nuevos estilos constructivos, sino que más bien encontró inspiración en la tradición del pasado, en los cánones eclesiásticos, en las preferencias de los autores, y en los gustos del clero y de los fieles. La historiografía arquitectónica comenzó a estar mucho más interesada en los protagonistas de la nueva arquitectura eclesiástica serbia entre 1870 y 1941: Ivackovic, Ilkic, Zivanovic, Ruvidic, Korunovic, Popovic, Deroko, Samojlov y Androsov. Gracias a una amplia gama de monografías y exposiciones, sus obras - que sirvieron de inspiración a los arquitectos modernos - comenzaron a ser estudiadas en profundidad. El congreso titulado «La tradición y la arquitectura eclesiástica serbia moderna» se celebró en el Museo de Artes Aplicadas de Belgrado en 1994, y resultó de suma importancia para la recuperación científica de ese tema histórico antes abandonado, además de servir para aclarar los conceptos esenciales de la nueva arquitectura eclesiástica. 

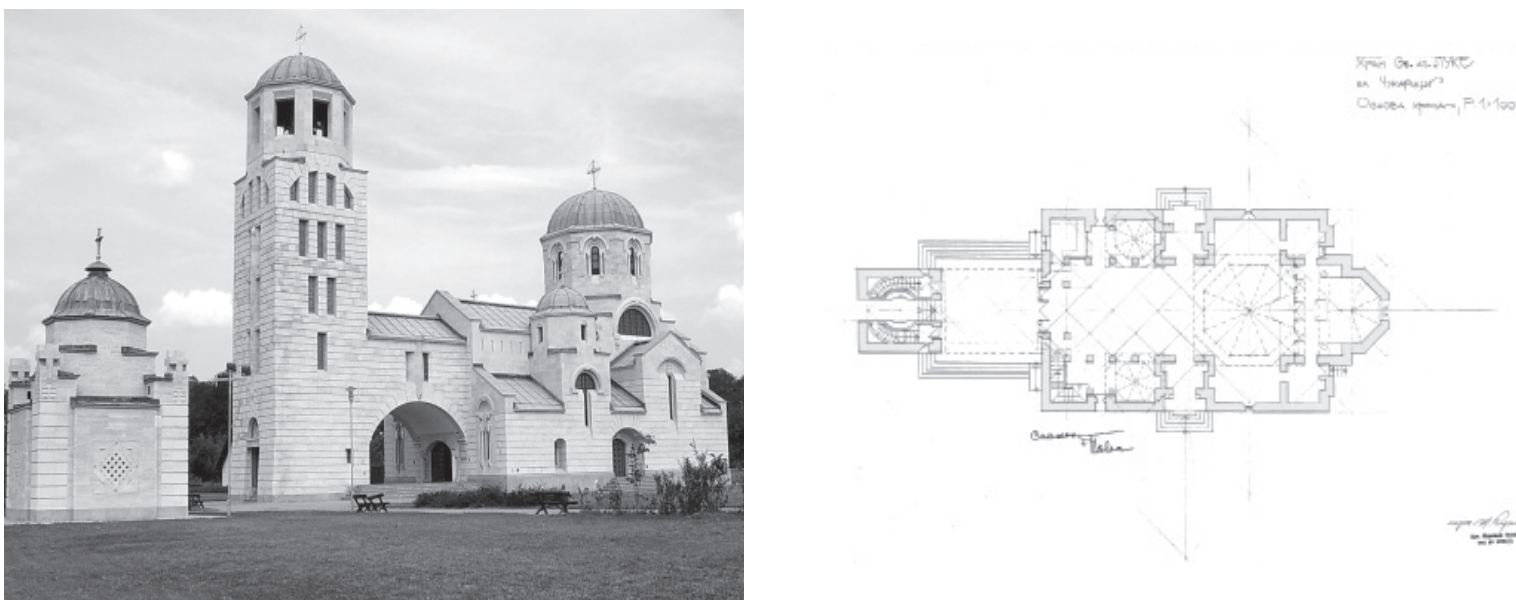

Figs. 3-4. Miladin Lukic, San Lucas, Belgrado, 1995/2003.

Fig. 5. Nebojsa Popovic, San Demetrio, Nuevo Belgrado, 1998/2001.

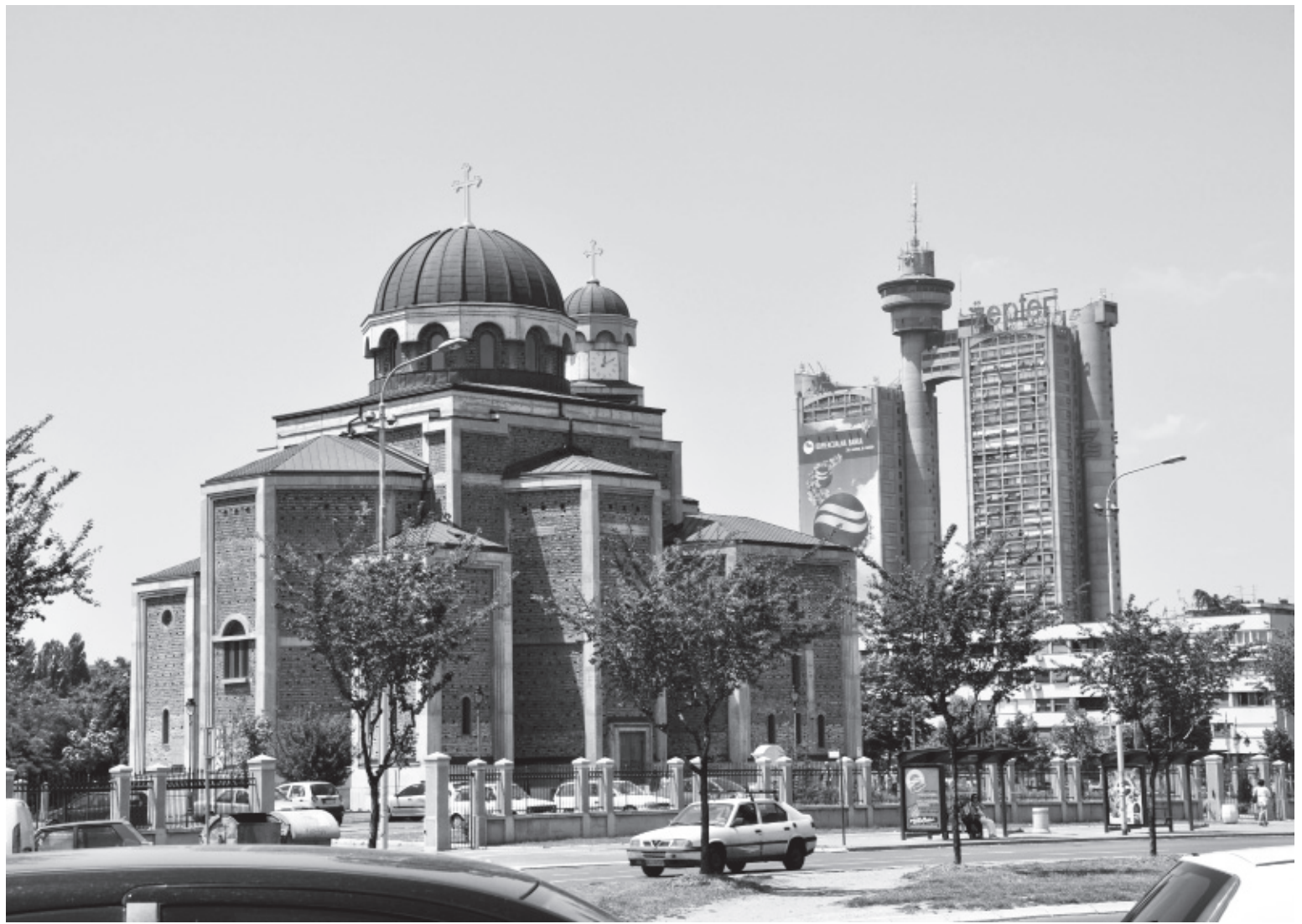




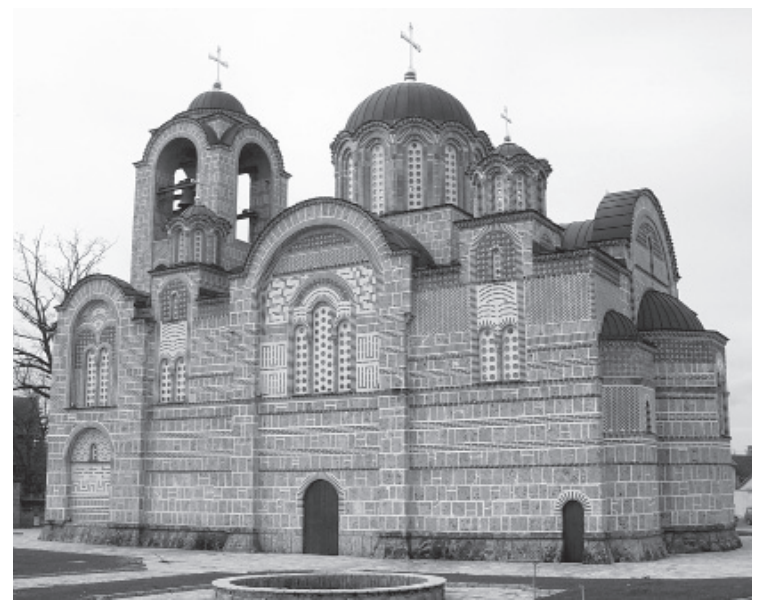

Fig. 6. Predrag Ristic, La Ascensión del Señor, Ub, h. 2000.

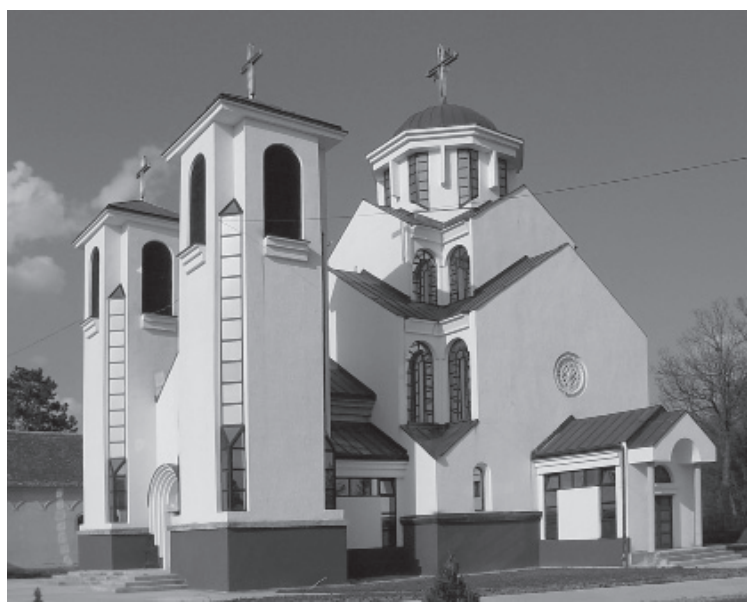

Fig. 7. Zoran Bundalo, San Miguel Arcángel, Jabucje, h. 1995.
La exposición celebrada en el mismo museo en 1995, titulada «Arte moderno ortodoxo serbio» fue de especial significación para continuar el desarrollo del arte sacro, siendo Dusan Milovanovic su comisario. Durante ese especial acontecimiento, se hizo pública la actitud oficial del patriarca de la Iglesia ortodoxa serbia, el Sr. Pavle. Probablemente su actitud se vio influida por la prolongada crisis de identidad de dicha Iglesia, en el sentido de que la ampliamente difundida arbitrariedad de los proyectos para iglesias no era bienvenida. Recalcó la importancia de la modestia y anonimato de los autores, y les instó a actuar de manera pasiva y humilde y a comprender y practicar los cánones religiosos en su trabajo profesional y en su vida personal. También recalcó que convenía construir iglesias de acuerdo con los monumentos más famosos de la arquitectura medieval serbia, como Gracanica, Kalenic o Lazarica, hasta que fuese inventado un nuevo estilo de construcción aceptable para la ortodoxia.

Por desgracia, paralelamente a dicho proceso —en el que la Iglesia ortodoxa serbia realizó grandes esfuerzos para compensar su prolongada falta de influencia cultural y recuperar su identidad, aumentando sus capacidades espaciales y haciéndolas encajar con las necesidades de la gente religiosa normal-, la sangrienta guerra civil ya se había desatado en el antiguo estado multinacional (1991/95 y 1998/99). En aquella guerra, las naciones en conflicto intentaron lograr sus objetivos nacionales por medio de la fuerza y la pura violencia. No solo fue una guerra por el territorio y la dominación política (que se suele denominar limpieza étnica), sino también una influencia confesional silenciosa, por la cual las naciones en conflicto profanaron los objetos religiosos del enemigo. Tras aquella primera ola de terrible destrucción, nunca antes vista, desgraciadamente, todo el proceso tuvo continuación en el área de Kosovo y Metohija (1999/2004).

Por otra parte, el concepto morfológico y estructural de la nueva arquitectura serbia desde la década de 1990 se dirigió principalmente a la recuperación de su identidad nacional, durante tanto tiempo abandonada. Esta era la razón de que las nuevas iglesias que se construían tuviesen un carácter nacional y geopolítico claramente distintivo, visible en las siluetas pero también en la composición y en los detalles. Dicho renacimiento confesional no fue rápido y unilateral, como podría parecer a primera vista, ni estuvo apoyado por las autoridades políticas en todas las zonas del antiguo estado. Además, estuvo principalmente canalizado hacia estrechos círculos eclesiásticos, culturales e intelectuales. La construcción de iglesias durante la guerra tuvo una dimensión significativamente nacionalista, excepto en lo que se refiere a la definición de sus propios territorios y la confirmación de sus derechos nacionales. En términos de su sentido programático, representaba la continuidad con las épocas pasadas de la arquitectura serbia, mien- 


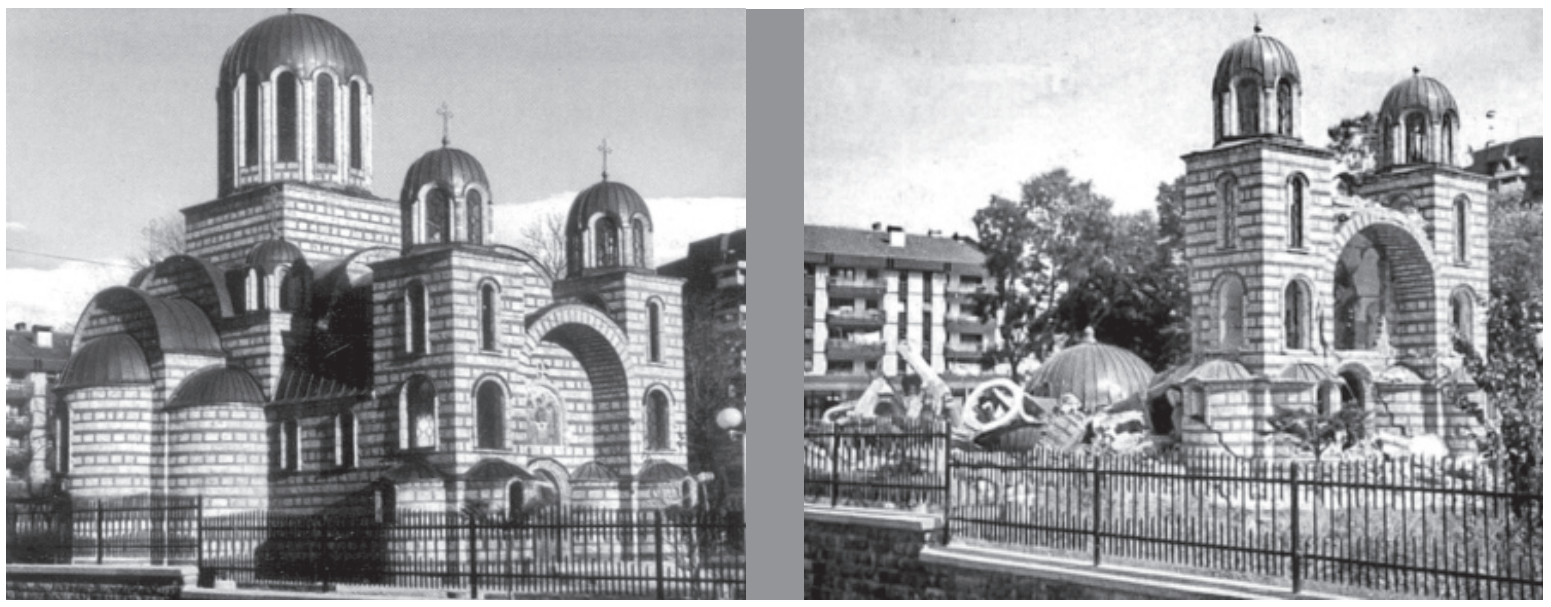

Fig. 8. Ljubisa Folic, Santísima Trinidad, Djakovica, 1999, antes y después de su destrucción.

tras que estilísticamente - al menos en algunos ejemplos- daba un gran paso adelante hacia la contemporaneidad en la que se construía. Cada barrio con iglesias estaba caracterizado por un concepto diferente que dependía mucho de las necesidades del clero, de las aspiraciones de los miembros del consejo eclesiástico, y también de los ágiles conservadores de iglesias y monasterios. Se habían popularizado el contextualismo y la tradición, de manera muy similar a lo que había ocurrido en periodo de entreguerras mundial, cuando se habían construido cientos de templos, además del concepto medieval serbio eclécticamente expresado. Al contrario que en aquel próspero período, se desarrolló evocadoramente un variado historicismo postmoderno, apoyado por el influjo de los nuevos materiales e instrumentos técnicos.

El nuevo historicismo serbio, orientado en muchos aspectos en contra de la globalización, juntó con los monumentos de la llamada Escuela de Rascia (fines del XII-mediados del XIV) algunos ejemplos de monasterios serbo-bizantinos ubicados principalmente en Kosovo y Metohija (siglo XIV), entre los cuales la mayoría evocaba las formas arquitectónicas de la Escuela de Moravia (finales del XIV-primera mitad del $\mathrm{XV}$ ). En términos de soluciones espaciales, el edificio eclesiástico estaba firmemente enraizado en las tradiciones serbia y bizantina que no variaban mucho con respecto a la estructura (interior de la iglesia, espacio alrededor del altar, capillas y, a veces, campanario al oeste), aunque con respecto al servicio de la iglesia, su transformación empezó hacia finales del siglo XVIII, lo cual provocó su modernización gradual. Como ya se ha mencionado, los ejemplos principales se hallaban en las formas representativas de la arquitectura medieval y más moderna (de entreguerras). Por otro lado, otros constructores más ambiciosos y representantes del clero eclesiástico expresaron su disposición hacia conceptos más liberales de la arquitectura externa, que seguía fuertemente controlada por los cánones tradicionales.

La Academia para el Arte y la Conservación contribuyó considerablemente al proceso, siendo fundada por la Iglesia ortodoxa serbia y contando con profesores que elaboraron creativamente programas para el tratamiento artístico de los nuevos espacios internos de las iglesias. Enriquecidos por el conocimiento, los líderes de la moderna arquitectura eclesiástica serbia —Predrag Ristic, Miladin Lukic, Mihajlo Mitrovic, Branko Pesic, Zoran Bundalo, Ljubica Bosnjak, Ljubisa Folic, Radoslav Prokic, Branislav Mitrovic, Sasa Budjevac, Spasoje Krunic, Miodrag Mladenovic y otros- consiguieron resultados aceptables, tanto para la Iglesia como para los críticos de arte.

Ubicado sobre el pico más elevado de la meseta de Vracar, el templo de San Sava se destaca en el paisaje de la ciudad de Belgrado (Fig. 1). Técnicamente y desde el punto de vista de su realización es una compleja 


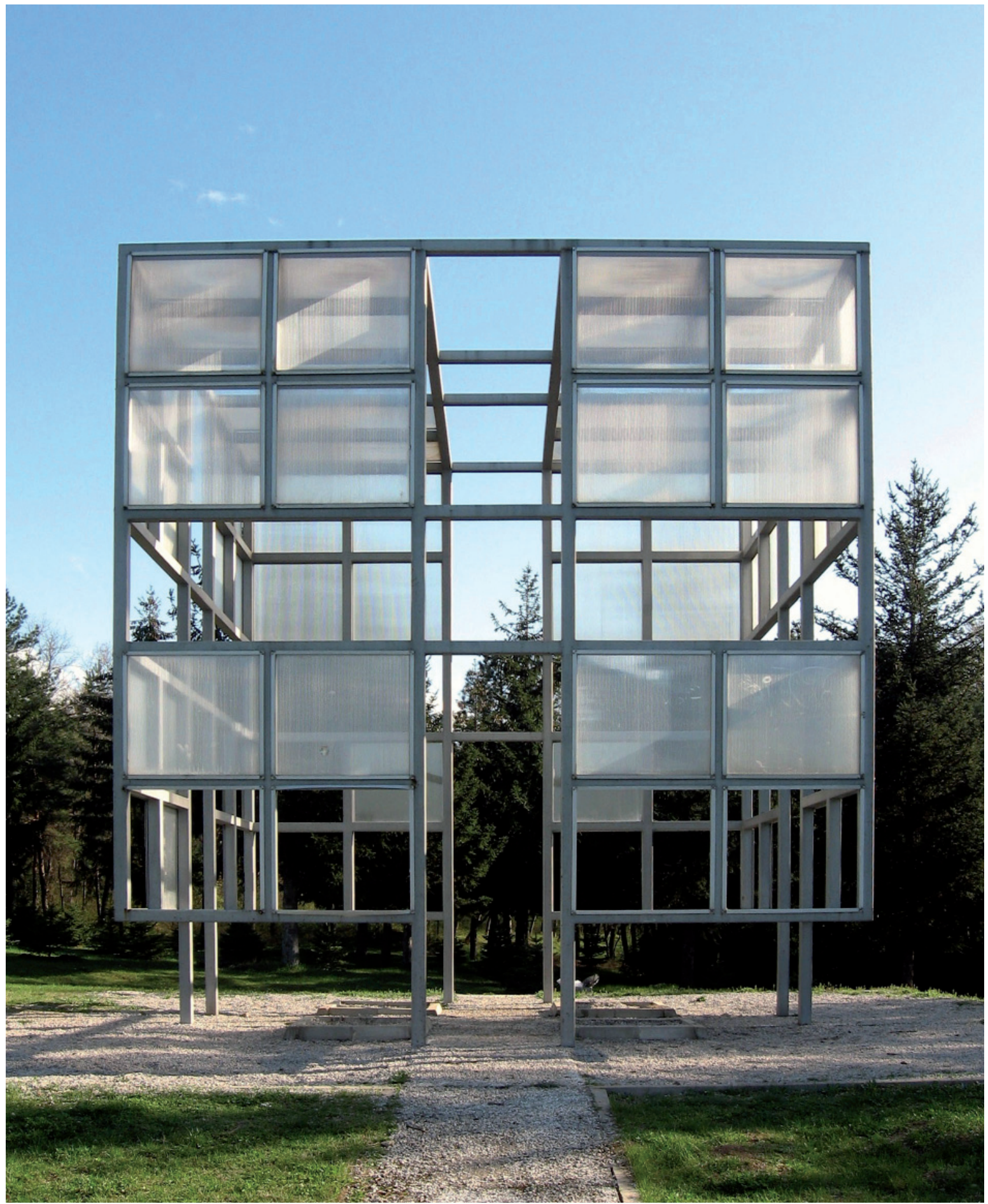


megaestructura, mientras que simbólicamente se ha convertido en un centro cultural y espiritual de la nación serbia y un bastión de continuidad en la secular tradición serbo-bizantina. Surgió de la fusión de dos proyectos presentados al concurso de 1926 (Bogdan Nestorovic y Aleksandar Deroko) como una síntesis de Santa Sofía de Estambul y el estilo serbio-bizantino del siglo XIV. Las obras de construcción comenzaron en 1985 y aún continúan, siendo actualmente los directores los arquitectos Branko Pesic y Vojislav Milovanovic. Pesic ha decidido usar una construcción de hormigón reforzado, después de neutralizar las zonas ya construidas con ladrillo, cubriéndolas con una moderna fachada de perfil plano recubierta de mármol blanco. Manteniendo la forma serbo-bizantina auténtica, introduce un tratamiento moderno de la fachada y del volumen, preservando la identidad esencial de la iglesia ortodoxa.

Con la iglesia de San Basilio de Ostrog (1996/2002) en Bezanijska Kosa (en la periferia del Nuevo Belgrado), Mihajlo Mitrovic, uno de los más importantes autores de la antigua generación, ha logrado con éxito aplicar sus habilidades al campo de la arquitectura sacra moderna (Fig. 2). Ha escogido una sencilla solución especial usando una plástica densa que enfatiza una gran iglesia circular. La iglesia presenta la forma de una rotonda continuada por anexos inferiores, un porche y un campanario al oeste, y un ábside trifolio tras el altar al este. El área circular desarrollada centralmente no posee elementos de apoyo. Por encima del amplio nicho de la portada, en posición ligeramente adelantada, hay un motivo decorativo importante: una cruz griega de un brazo en el óculo. A pesar de que las críticas más frecuentes se han centrado en la subordinación proporcional de la rotunda bóveda a la estructura de un volumen básico — además de en la excesiva atención al detalle—-, se establece un diálogo con las escasas pero efectivas iglesias circulares construidas en Belgrado y Sarajevo en el periodo de entreguerras, y también con las iglesias de la costa del Adriático construidas durante la Edad Media.

La iglesia de San Lucas, construida en la Ciudad del Cine, a las afueras de Belgrado (1995/2003; Fig. 3) por el arquitecto conservacionista Miladin Lukic, ganador de un gran concurso de expertos, representa un ejemplo único de la Escuela Raska, la más antigua e importante para el completo desarrollo de la construcción de igle-

Fig. 9. (En página anterior) Sasa Budjevac, Capilla conmemorativa, Bubanj-Nis, 2002/03 sias en el medievo serbio. En su concepto espacial, en su tratamiento exterior, en la composición general y en su poderosa silueta, la iglesia evoca toda una época de los antiguos monumentos de la Escuela de Rascia, especialmente los del siglo XIII, como las iglesias de los monasterios de Zica, Sopocani y Gradac, caracterizadas por su única síntesis de la morfología románico-bizantina. A la solución compositiva original y a los efectivos detalles se añadió con éxito un patrón reconocible como medieval, enfatizándolo de manera evocadora y asociativa. Su planificación total no fue ecléctica, porque los elementos originales fueron pre-estilizados y transformados por el lenguaje de la arquitectura postmoderna de fines del siglo XX. El significado tradicional de la bóveda superior sobre la nave se ha mantenido, a pesar del énfasis otorgado a las bóvedas menores inferiores con las paredes rematadas en gablete de los anexos laterales, que efectivamente atraviesa la pseudo forma de tres naves de la masa básica de la iglesia (Fig. 4). Inspirado por la silueta de la pseudo-basílica de Sopocani en su cuerpo principal, además de por la figura de un alto campanario y segmento de arco que los conecta, el autor ha conseguido formas novedosas. $\mathrm{Y}$ al combinar las aberturas semicirculares y en forma de cruz estilizadas, ha revivido de modo efectivo las fachadas de la iglesia cerrada tradicional.

El significado histórico de la iglesia de San Demetrio, construida entre 1998 y 2001 en el Nuevo Belgrado (Fig. 5) es visible en el hecho de que fue la primera en ser construida con un plan coherente con un distrito arquitectónico urbano famoso por sus numerosos bloques de pisos y estructuras administrativas y empresariales. El edificio es el resultado de un concurso con varias soluciones originales. Ganó la obra del arquitecto Nebojsa Popovic, que fue muy valorada desde el punto de vista funcional y un buen complemento de la totalidad circundante. Su concepto espacial, planeado centralmente, está enfatizado por su fachada y no tiene rival en la arquitectura serbia moderna. El objeto representa una totalidad abruptamente dividida y con fachadas lisas rústicas pero elegantes. Hay una composición simplificada de masas cubistas de aspecto moderno, agrupadas centralmente y escalonadas como una pirámide, acabada por las bóvedas serbias de la iglesia y del campanario. La iglesia casi encaja en la modernidad circundante del Nuevo Belgrado, cuya zona central fue planificada a finales de los años 60 del siglo XX siguiendo el ejemplo 


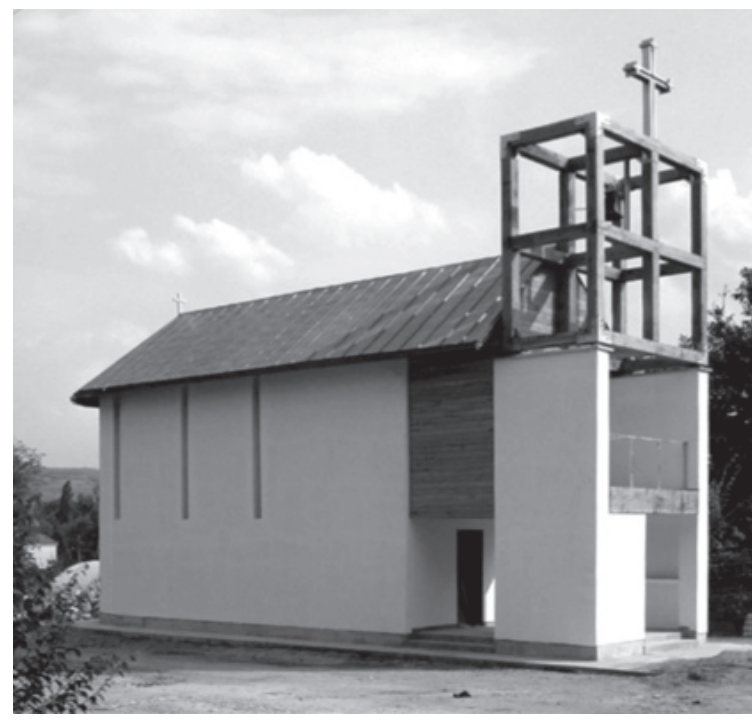

del centro administrativo de Brasilia. Debido al respeto por la orientación tradicional del altar hacia el este, fue imposible permitir el acceso directo a la entrada principal desde la carretera, lo cual de algún modo redujo su significado en el entorno urbano. Asimismo, el contraste demasiado poderoso entre las formas modernas y las tradicionales, visible en la silueta de la iglesia y en la presentación plástica, reduce también su cualidad principalmente funcional.

Predrag Ristic, arquitecto ya establecido como constructor de una serie de iglesias en la diáspora serbia y en su patria durante el régimen comunista en Yugoslavia, ha desarrollado libremente sus empresas desde 1990. Se sumó de manera entusiasta a los nuevos rumbos de la arquitectura sacra, destacando como líder y experto en las antiguas técnicas y estándares. Ha desarrollado un historicismo evocador y literal, deseable para los tradicionalistas pero aceptable en muchos segmentos para el público interesado en la innovación. Su estilo está fuertemente enraizado en la tradición serbo-bizantina y resulta geopolíticamente nacional. Aparte de sus monumentales iglesias urbanas (Podgorica, Ub, Trebinje, Krnjaca, Apatin), construyó una serie de capillas y parroquias en los últimos años. Durante la guerra civil, catorce de sus iglesias fueron destruidas en Croacia y Bosnia-Herzegovina.

En la iglesia de la Ascensión del Señor en Ub (Fig. 6), Ristic insiste en la reminiscencia literal de todo el
Fig. 10. Branislav Mitrovic, capilla privada, Stipina-Knjaževac, 2003/05

estilo serbo-bizantino en la arquitectura del siglo XIV, combinando los elementos de sus monumentos más representativos construidos en Kosovo y Metohija. El plano de base fue realizado de acuerdo con el espacio abovedado de tres naves de la iglesia del monasterio de los Santos Arcángeles cerca de Prizren (1343/52), con la cruz de brazos planos inscrita del emperador serbio Dusan. La reconstrucción ideal que hizo el autor del mausoleo derribado de Dusan — que él defendió durante años en los círculos de expertos-, sirvió como cimiento morfológico-estructural de la iglesia de Ub. Ristic añade también un campanario de dos pisos por encima del nártex, de acuerdo con la parte oeste de la iglesia de cinco naves y cinco bóvedas de la Madre de Dios en Prizren (1306/10). Ello permitió el espacio adicional en el interior del nártex para un anexo lateral en el lado sur. Sobre el nártex está el espacio para la galería del coro que se abre hacia la nave en el interior. La evocación del estilo serbo-bizantino predomina en las fachadas, aunque la iglesia se construyó de acuerdo con las técnicas modernas. Fue totalmente proyectada en hormigón armado, recubierto por fuera con una capa de carbonato de calcio cristalino, y ladrillos decorativos con una colorida danza de formas ornamentales conseguidas gracias a la combinación de ambos materiales. La bóveda se compuso de dos capas y dos sectores de hormigón reforzado, colocados sobre el tambor y unidos. 
La iglesia de San Miguel Arcángel en Jabucje (de la última década del siglo XX) destaca en la obra sacra del arquitecto Zoran Bundalo, representando una compleja evocación histórica y post-moderna de todas las escuelas de la arquitectura medieval serbia (Fig. 7). Resulta inusual su silueta de doble campanario en el cuerpo frontal, que corresponde con la estructura de capas piramidal del cuerpo central de la iglesia, cuyos enormes muros de gablete fueron perforados con los nuevos y efectivos rosetones del estilo de Morava.

Como arquitecto e intérprete de la antigua arquitectura, en su obra, Ljubisa Folic intenta también modernizar los conceptos establecidos de la arquitectura serbia tradicional (iglesias en Zarkovo, Piskote, Zapska, cerca de Pozega y Leposavic en Serbia y Ljubinje en Croacia). Aplicando nuevos materiales, técnicas y estructuras, tuvo éxito en una serie de edificios, desarrollando un historicismo más literal y evocador basado en el estudio original de los elementos esféricos y de los arcos. Algunas de sus iglesias monumentales, construidas en Kosovo y Metohija, fueron sistemáticamente destruidas por los extremistas albaneses. Así, por ejemplo, en el lugar donde se había construido la iglesia de la Santísima Trinidad en Djakovica (1999; Fig. 8), hoy se levanta un parque, después de años de destrucción total.

Con la capilla de Bubanj (2002/03; Fig. 9) cerca de Nis, construida como parte del centro conmemorativo existente, el arquitecto Sasa Budjevac inició un nuevo rumbo alejado radicalmente de la historia de la arquitectura sacra serbia. Con esta construcción abstracta en forma de cubo de cristal, estableció un lenguaje plástico de meta-formas, enriquecido con un simbolismo cristiano distinguido pero simplificado. Su estructura abierta y no jerárquica completamente distanciada de cualquier patrón medieval, está perforada por aberturas cruciformes que crean un medio de contemplación espiritual, casi una narración didáctica e histórica reducida a un signo en su identidad.
El arquitecto serbio más significativo y premiado de las dos últimas décadas es Branislav Mitrovic, autor de una pequeña iglesia en Stipina, cerca de Knjaževac (2003/05, al este del país), uniendo exitosamente los rumbos de la nueva arquitectura sacra (Fig. 10). Además de trabajar en distintos campos de la arquitectura profana, ha adquirido una expresión individual única, adelantándose al gusto y a los tiempos de su entorno, y recibiendo el mayor reconocimiento de los expertos. Esta pequeña iglesia longitudinal y compositivamente compacta fue proyectada en un estilo arcaizante (las fachadas interior, lateral y del altar), y está caracterizada por la pureza formal, la sencillez y el simbolismo efectivo de una cruz que se distingue al frente. La impresión de espiritualidad y de modestia no intrusiva de esta iglesia proviene sobre todo de la combinación de las formas abstractas y expresivas. Como resultado de esta innovadora aproximación, nos mantendremos a la espera de nuevos intentos ambiciosos y liberales.

\section{BIBLIOGRAFÍA}

Borislav Stojkov and Zoran Manevic (eds.), «Tradition and contemporary Serbian Church Engineering (Традиција и савремено српско црквено градитељство)», Belgrado, 1995.

Duљan Milovanovic, «Contemporary Orthodox Serbian Art (Савремена православна српска уметност)», Belgrado, 1995.

Tanja Damljanovic, «The Orthodox Temple in Contemporary Context», en: «Architecture-Urbanism at the turn of the III Millennium, vol. 1», (Actas del congreso), Belgrado, 1996, pág. 537-539.

Aleksandar Kadijevic, «One century for National Style Searchings in Serbian Architecture -the middle of the 19.--the middle of the 20th c. (Један век тражења националног стила у српској архитектури, средина 19-средина 20. века)», Belgrado, 2007.

Miodrag Jovanovic, «Serbian Ecclesiastical Architecture and Paintings in the Last 300 Years (Српско црквено градитељство и сликарство новијег доба)», Belgrado, 2007.

Ljiljana Miletic-Abramovic, «Parallels and Contrasts. Serbian Architecture 1980-2005 (Паралеле и контрасти. Српска архитектура 1980-2005)», Belgrado, 2007.

Zoran Manevic (ed.), «Lexikon of Builders (Лексикон неимара)», Belgrado, 2008. 